\title{
Interventional Radiology during the Second Wave of COVID-19-Stories from the Trenches
}

\author{
Shyamkumar N. Keshava Sanjeeva Kalva² \\ 1 Department of Interventional Radiology, Division of Clinical \\ Radiology, Christian Medical College, Vellore, Tamil Nadu, India \\ 2 Division of Interventional Radiology, Department of Radiology, \\ Massachusetts General Hospital, Boston, Massachusetts, United \\ States
}

J Clin Interv Radiol ISVIR 2021;5:69-69.

The ongoing second wave of COVID-19 has significantly affected the people of India. In earlier publications, we highlighted the impact of COVID-19 on interventional radiology (IR) practice. In this editorial, we share a few stories of IR practitioners who have diversified their role to contribute toward COVID-19 care. These were gathered informally with the help of various WhatsApp groups.

Dr. C.G. Sharthkumar, a practicing neuroradiologist from Bangalore, describes his non-IR role in COVID-19 care. He worked as a primary physician in COVID-19 wards. This role included clinical evaluation, treatment, and follow-up of the patients. He took part in the image interpretation of chest radiographs and high-resolution CT (HRCT) chest of COVID-19 patients. He introduced an innovative color-coding to display the severity of lung lesions, which not only helped in the initial triaging of patients but also making decisions on subsequent care during rounds. He contributed to counselling of patients and family members too. He conducted academic sessions to enhance understanding of the disease and its management among the medical practitioners and ancillary staff. He reported that a few IR practitioners volunteered for the purpose of telecounselling of patients and the public. A few others provided community counselling in order to improve the understanding of the process of COVID-19 vaccination.

Dr. Atul Revatkar and Dr. Rajesh Mundadha practice in Nagpur. They dedicated their IR hospital ("Pulse Clinic and Hospital") consisting of 20 beds to COVID-19 care by converting it to a COVID specialty hospital. There were several challenges in both manpower and infrastructure. These included the availability of copper pipes, connectors, flow meters, oxygen, life-saving equipment, and drugs. Some of the supplies had to be procured from different cities and the lockdowns restricted transportation. The managerial responsibilities included coordinating with the government and interacting with several public members. They attended to hundreds of phone calls from the public on a regular

Dol https://doi.org/ 10.1055/s-0041-1731121 ISSN 2457-0214

\begin{abstract}
Address for correspondence Shyamkumar N. Keshava, DMRD, DNB, FRCR, FRANZCR, Department of Interventional Radiology, Division of Clinical Radiology, Christian Medical College, Ida Scudder Road, Vellore-632004, Tamil Nadu, India

(e-mail: shyamkumar.n.keshava@gmail.com).
\end{abstract}

basis. Anxiety, sorrow, and panic were common. Dr. Rajesh Mundhada suggested the formation of a national administrative cadre-Indian Medical Services-in line with the Indian Administrative Services for national planning and implementation of health services.

Dr. Shuvro Roy Choudhury practices in a large tertiary hospital in Kolkata. During the early part of the first wave, when reverse transcription-polymerase chain reaction (RT-PCR) testing was inconsistent, he developed a pathway for patient admission by incorporating HRCT in the diagnostic algorithm, which was later adopted nationally. A similar pathway was also developed for preoperative screening. Where CT scan access was suboptimal, he developed and reported pathways using chest radiographs. He was actively involved in educating radiologists and other physicians on the role of imaging during the management of COVID-19. During the second peak as well, he continues to offer teleconsultation and patient support, some on doctor-led voluntary platforms.

Dr. Hemanth Deshmukh, IR specialist and director of King Edward Memorial Hospital, Mumbai, was actively involved in administrative activities pertaining to COVID-19 care. ${ }^{1} \mathrm{He}$ highlighted the importance of brainstorming, optimal planning, teamwork, continuous vigilance on patient inflow, and being vigilant with regard to potential high demand of any equipment or medicine. His work was target-oriented and with no time boundaries.

These handpicked examples highlight the pragmatic role played by the IR community to cater to the broader and urgent need of society, which emerged on account of the COVID-19 pandemic.

\section{References}

1 Deshmukh, H. COVID-19: Experience from KEM Hospital, Mumbai. J Clin Interv Radiol ISVIR 2021. Doi: 10.1055/s-0041-1731120

(c) 2021. Indian Society of Vascular and Interventional Radiology. This is an open access article published by Thieme under the terms of the Creative Commons Attribution-NonDerivative-NonCommercial-License, permitting copying and reproduction so long as the original work is given appropriate credit. Contents may not be used for commercial purposes, or adapted, remixed, transformed or built upon. (https://creativecommons.org/licenses/by-nc-nd/4.0/).

Thieme Medical and Scientific Publishers Pvt. Ltd. A-12, 2nd Floor, Sector 2, Noida-201301 UP, India 